\title{
STIMULATORY EFFECT OF THE LYSOSOMAL STABILIZER, CHLOROQUINE, ON THE RESPIRATION AND MOTILITY OF FRESH AND AGED BOVINE SPERMATOZOA*
}

\author{
CHARLES NORMAN $\dagger$ AND SAMSON GOMBE \\ Department of Animal Physiology, Chiromo, University of Nairobi, \\ P.O. Box 30197, Nairobi, Kenya
}

(Received 19th November 1974)

\begin{abstract}
Summary. The lysosomal stabilizer and anti-malarial agent, chloroquine, stimulated the respiration and motility of fresh and aged bovine spermatozoa stored in vitro. Duplication of these effects by the phosphodiesterase inhibitors, theophylline and caffeine, suggested that enhancement of sperm activity by chloroquine may be mediated by cyclic AMP.
\end{abstract}

\section{INTRODUCTION}

While studying the influence of various drugs, hormones and vitamins on the latency of acrosomal enzymes in ejaculated bovine spermatozoa stored in vitro, we observed that the anti-malarial agent and lysosomal stabilizer, chloroquine disphosphate (Weissman, 1969), markedly stimulated sperm respiration and motility. This reaction to chloroquine seemed to parallel the recently described stimulatory influence of phosphodiesterase inhibitors, such as theophylline and caffeine, exogenous cyclic AMP and derivatives of cyclic AMP on sperm metabolism and motility, suggesting that chloroquine might be acting either directly or indirectly on the adenyl cyclase system (Garbers et al., 1971a, b; Hoskins, 1973; Tash \& Mann, 1973).

Since one of our principal research aims was to improve the survival time and fertilizing capacity of preserved bull spermatozoa, we decided to use a coconut milk extender (CME) rather than chemically defined media for testing the effect of chloroquine on sperm function in the laboratory. This extender (Norman et al., 1962) is used in East Africa to preserve bovine spermatozoa at ambient temperatures for several days before artificial insemination into dairy cattle.

\section{MATERIALS AND METHODS}

Semen was collected once a week from one of six bulls for 7 months. The freshly collected spermatozoa were suspended, without washing, in CME, both

* Reprint requests to Dr S. Gombe.

$\dagger$ Deceased 
in the presence and absence of $7 \%$ egg yolk. Before dilution sperm concentration was determined photometrically, and the proportion of motile cells as well as the qualitative aspects of their movements were assessed microscopically at $37^{\circ} \mathrm{C}$. Sperm motility was graded according to the following system: a score of 0 (non-motile) to 5 (excellent progression) was used to rate the force of directional movements, a score of 0 (none) to $10(100 \%)$ was used to denote the estimated number of motile cells in suspension. These parameters were graded in individual samples by unbiased observers and their sum used as a single expression of motility. Final concentrations of $50 \times 10^{6}$ spermatozoa $/ \mathrm{ml}$ were used to measure initial uptake, and of $25 \times 10^{6}$ spermatozoa $/ \mathrm{ml}$ to measure the oxygen consumption, motility and survival time of ageing spermatozoa. The $\mathrm{O}_{2}$ consumption in $4.5 \mathrm{ml}$ aliquots of sperm suspension was measured with a Yellow Spring Instrument (YSI) Model 55 Biological Oxygen Monitor connected to a YSI Model $80 \mathrm{~A}$ recorder for 10 to $15 \mathrm{~min}$ at $37^{\circ} \mathrm{C}$ and expressed as $\mathrm{Zo}_{2}\left(\mu 1 \mathrm{O}_{2}\right.$ consumed by $1 \times 10^{8}$ spermatozoa/hr at $\left.37^{\circ} \mathrm{C}\right)$.

Experimental drugs (approximately $10^{-4} \mathrm{M}$ ) were dissolved in CME and the $\mathrm{pH}$ of the solutions adjusted to 7.4. After the $\mathrm{O}_{2}$ consumption of a sperm suspension had been measured for $15 \mathrm{~min}, 0.02 \mathrm{ml}$ of an experimental solution or of CME was introduced into the sperm suspension through a relief hole in the oxygen electrode. Oxygen consumption for the subsequent 15 min constituted the experimental phase.

Smears stained with eosin-nigrosin (Norman et al., 1962) were used to determine the proportion of dead spermatozoa.

\section{RESULTS}

Text-figures $1(\mathrm{a})$ and 1 (b) show that the addition of $0.5 \mathrm{~mm}$-chloroquine to CME, with and without egg yolk, consistently increased the respiration of
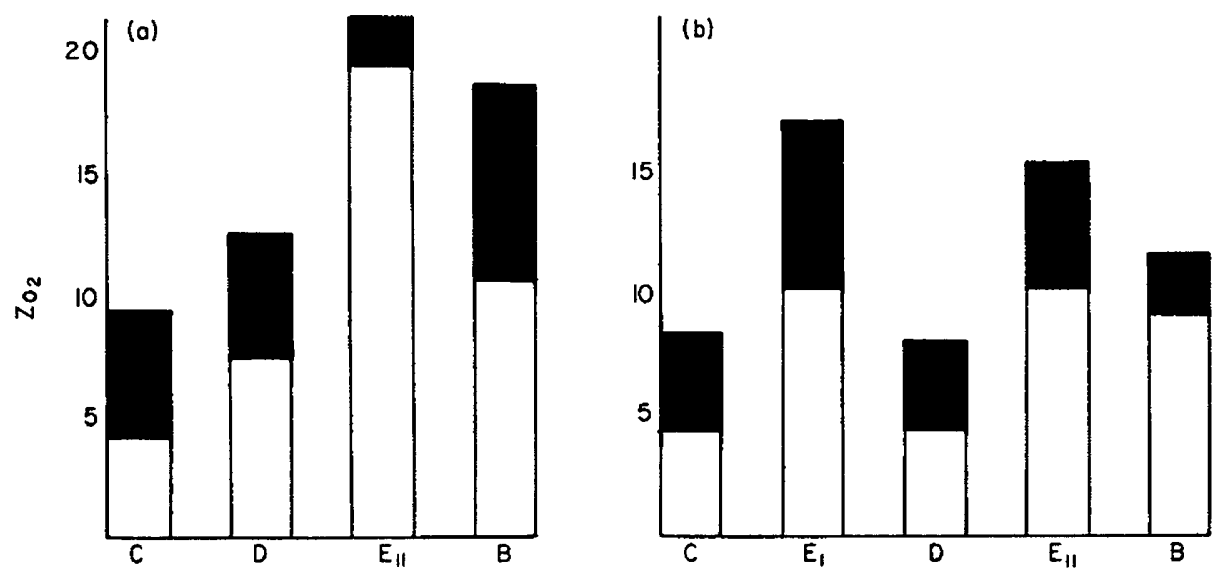

Bulls

TEXT-FIG. 1. The effect of $0.54 \mathrm{~mm}$-chloroquine on the respiration of fresh spermatozoa collected from four different bulls and diluted in (a) CME containing $7 \%$ egg yolk, and (b) $C M E$ without egg yolk. $E_{1}$ and $E_{2}$ represent ejaculates from the same bull collected on two separate occasions. The solid portion of each column indicates the increase in respiration due to chloroquine. $\mathrm{Zo}_{2}=\mu \mathrm{l} \mathrm{O} \mathrm{O}_{2}$ consumed by $100 \times 10^{6}$ spermatozoa/hr at at $37^{\circ} \mathrm{C}$. 
freshly collected spermatozoa from four different bulls. The variations of $\mathrm{Zo}_{2}$ of control and experimental aliquots of the sperm suspension from any one bull were small.

Similarly the data in Table 1 show that the addition of chloroquine substantially raised the metabolic rate of $2 \frac{1}{2}$ - to 7-day-old spermatozoa above the level of the initial rate. This table further demonstrates that chloroquine elicited a relatively greater rise when the $\mathrm{Zo}_{2}$ was low than when it was high; that is in poor or in ageing semen.

Table 1. Respiration ( $\mu \mathrm{l} \mathrm{O}_{2}$ consumed by $100 \times 10^{6}$ spermatozoa $/ \mathrm{hr}$ at $37^{\circ} \mathrm{C}$ ) of high quality and poor quality bull spermatozoa (judged on degree of motility and proportion live) suspended in CME with egg yolk before and immediately after addition of a single dose of $0.54 \mathrm{~mm}$-chloroquine at different times after ejaculation

\begin{tabular}{|c|c|c|c|c|c|c|c|c|}
\hline & \multicolumn{8}{|c|}{ Age of spermatozoa (days) } \\
\hline & \multicolumn{2}{|c|}{0} & \multicolumn{2}{|c|}{$2 \cdot 5$} & \multicolumn{2}{|c|}{4} & \multicolumn{2}{|c|}{7} \\
\hline & Control & $\begin{array}{c}\% \\
\text { Increase* }\end{array}$ & Control & $\stackrel{\%}{\%}$ Increase $^{*}$ & Control & $\stackrel{\%}{\text { Increase }}$ & Contral & $\stackrel{\%}{\%}$ \\
\hline $\begin{array}{l}\text { Poor quality } \\
\text { spermatozoa }\end{array}$ & 8 & 155 & 8 & 138 & & & 7 & 157 \\
\hline $\begin{array}{l}\text { High quality } \\
\text { spermatozoa }\end{array}$ & 19 & 118 & & & 12 & 150 & & \\
\hline
\end{tabular}

Only one observation was made for each pair of values.

* The control values are taken as $100 \%$.

Text-figure 2 illustrates the rejuvenating action of chloroquine on fresh and aged spermatozoa. The striking effect of chloroquine in increasing the force and frequency of sperm tail flagellation was particularly noticeable in 1- to 7-dayold spermatozoa. Spermatozoa kept for as long as 7 days regained or exceeded the progressive force of their initial movements immediately after receiving a single dose of chloroquine. This corresponded well with the constancy of the live/dead sperm ratios for the first 7 days. The kinetic activity in fresh spermatozoa stimulated by chloroquine remained high for 48 to $72 \mathrm{hr}$ and then dropped below the control level. The intensity and the duration of this stimulatory effect diminished progressively as the sperm cells aged. Once motility declined as a result of a single activating dose of chloroquine it could not be restimulated by subsequent additions of chloroquine. Treatment with prednisone or cortisone had no effect on sperm motility.

The similarity in the magnitude of the metabolic response of spermatozoa to approximately $10^{-4} \mathrm{M}$ concentrations of chloroquine $(0.54 \mathrm{~mm})$, theophylline $(0.19 \mathrm{~m} \mathrm{M})$ and caffeine $(0.32 \mathrm{~mm})$ is shown in Text-fig. 3(b). All three compounds enhanced the strength and speed of the directional movements (Text-fig. 3a), but the response of the spermatozoa to theophylline and caffeine was instantaneous, whereas the potentiating effect of chloroquine became maximal after only 1 to $2 \mathrm{~min}$ on the warming stage. The tail movement in the presence of the phosphodiesterase inhibitors appeared three-dimensional or helical, whereas the movement generated after chloroquine treatment seemed mainly two 
dimensional, with the tail vigorously lashing about from side to side. High concentrations of imidazole $(100 \mathrm{~mm})$, purportedly a phosphodiesterase activator, paradoxically increased the vigour of sperm movements, but these forceful movements were either circular or non-progressive (vibratory).

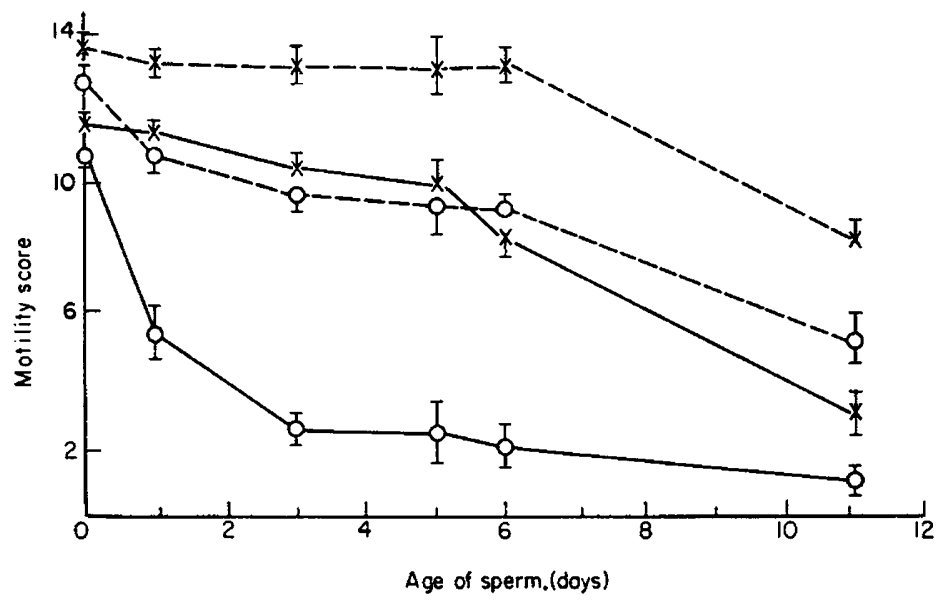

Text-FIG. 2. The motility of spermatozoa before $(-)$ and immediately after $(-\rightarrow-)$ a single dose of $0.54 \mathrm{mM}$-chloroquine at various times after ejaculation. $O$, GME without egg yolk; $x$, CME with egg yolk. Each point represents the mean \pm S.E. of six observations.
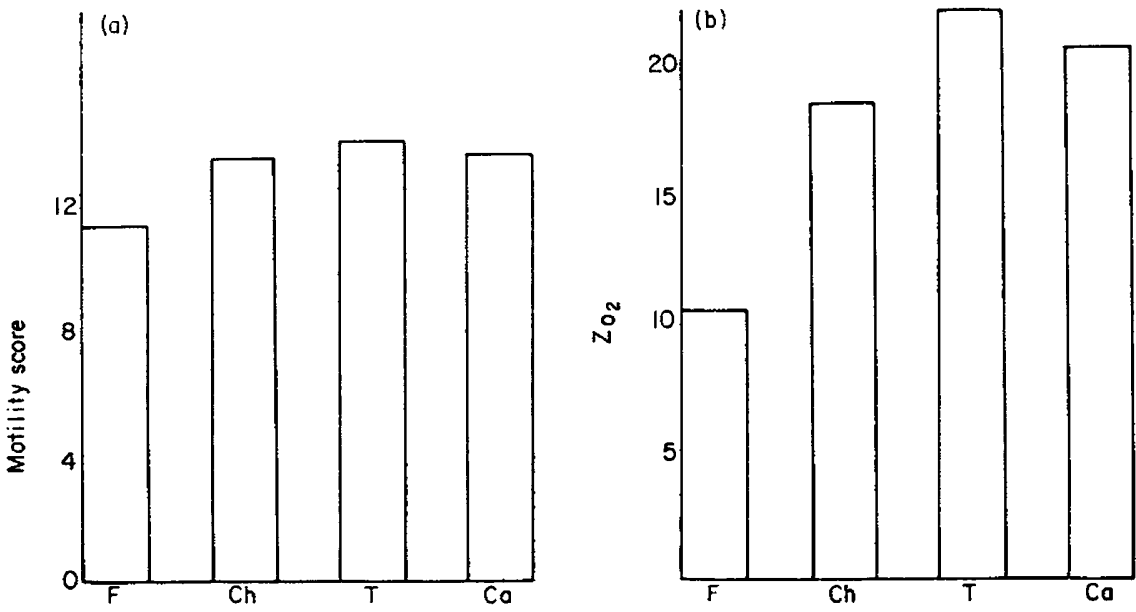

Text-rig. 3. Comparison of the stimulatory action of $0.54 \mathrm{~mm}$-chloroquine $(\mathrm{Ch}) ; 0.19$ mM-theophylline (T) and 0.32 caffeine (Ca) on (a) the motility and (b) respiration of fresh spermatozoa (F) suspended in $\mathrm{CME}$ containing $7 \%$ egg yolk. $\mathrm{ZO}_{2}=\mu \mathrm{l} \mathrm{O}_{2}$ consumed by $100 \times 10^{6}$ spermatozoa/hr at $37^{\circ} \mathrm{C}$.

The rapid decline in motility which usually followed the thawing of frozen spermatozoa could be forestalled by the addition of the phosphodiesterase inhibitors or chloroquine. Their order of effectiveness in preventing the detrimental effect of post-thawing temperature shock on progressive motility was theophylline $>$ caffeine $>$ chloroquine. 


\section{DISCUSSION}

The initial finding reported here on the activating influence of chloroquine on sperm respiration and motility and on its presumptive relationship to the phosphodiesterase inhibitors adds a new dimension to the multiple role of chloroquine as a lysosomal stabilizer, anti-malarial and anti-inflammatory agent. The finding that chloroquine can effectively reduce the ratio of ATP to other adenine nucleotides (energy charge) in the adenylate pool supports the theory that synthetic, non-steroidal, anti-inflammatory agents stimulate oxidative metabolism, thereby removing the ATP required by the inflammatory process (Whitehouse \& Leader, 1967).

As far as we know, this is the first demonstration that chloroquine can stimulate respiration and motility in fresh and aged bovine spermatozoa. The demonstration that chloroquine elicited a relatively greater rise in metabolic activity when the initial $\mathrm{Zo}_{2}$ was low than when it was high would seem to indicate that the metabolic processes in good and poor quality spermatozoa are not inherently different but that the rate at which these processes operate are regulated differently. Hence, poor quality spermatozoa appear to have the capacity to become better quality spermatozoa.

The decline in progressive motility after 7 days of storage at ambient temperatures may be associated with a corresponding decrease in the live:dead sperm ratio observed at this time. It may also be correlated with the gradual exhaustion of some vital endogenous reserve in a highly differentiated cell which has lost its capacity for protein synthesis.

Whether or not chloroquine can also increase the fertilizing ability of bovine spermatozoa incapacitated by age or stress remains to be clarified.

The data support the assumption that chloroquine and the cyclic AMP phosphodiesterase inhibitors, theophylline and caffeine, exert a common effect on the $\mathrm{O}_{2}$ uptake and kinetic activity of spermatozoa; however, the modes of action may be different. Experiments are being conducted to determine if chloroquine also shares a common mechanism of action with the methylxanthine phosphodiesterase inhibitors.

\section{ACKNOWLEDGMENTS}

We thank Dr I. E. Muriithi, Director of Veterinary services of Kenya and Dr D. E. Mbogo of the Central Artificial Insemination Service (CAIS) for their valuable cooperation and assistance. This work was supported in part by the National Science Foundation (SEED Program) and the Population Council of New York. We also thank Dr V. Mbaya of the Department of Veterinary Biochemistry, University of Nairobi, for her helpful suggestions and the loan of some equipment and material.

\section{REFERENCES}

Garbers, D.L., First, N.L., Sullivan, J.J. \& LARdy, H.A. (1971a) Stimulation and maintenance of ejaculated bovine spermatozoan respiration and motility by caffeine. Biol. Reprod. 5, 336-339.

GARBers, D.L., Lust, W.D., First, N.L. \& LARDY, H.A. (1971b) Effects of phosphodiesterase inhibitors and cyclic nucleotides on sperm respiration and motility. Biochemistry, N.r. 10, 1825-1831. 
Hoskins, D.D. (1973) Adenine nucleotide mediation of fructolysis and motility in bovine epididymal spermatozoa. 7. biol. Chem. 248, 1135-1140.

Norman, G., Johnson, C.E., Porterfield, I.D., Goldberg, E., Dunbar, R.S., Jr, Min, H.S. \& Dunn, H.O. (1962) Survival and fertility of bovine sperm kept at variable temperatures in coconut milk extender. F. agric. Sci., Camb. 59, 33-39.

TASH, J.S. \& MANN, T. (1973) Adenosine $3^{\prime}: 5^{\prime}$-cyclic monophosphate in relation to motility and senescence of spermatozoa. Proc. $R$. Soc. B 184, 109-114.

Weissmann, G. (1969) The effect of steroids and drugs on lysosomes. In The Role of Lysosomes in Biology and Pathology, Vol. 1, pp. 276-294. Eds J. T. Dingle \& H. B. Fell. North Holland, Amsterdam.

Whitehouse, N.W. \& LeAder, J.E. (1967) Biochemical properties of antiinflammatory drugs. IX. Uncoupling of oxidative phosphorylation and inhibition of a thiol enzyme (papin) by some cyclic B-diones and ninhydrin. Biochem. Pharmacol. 16, 537-551. 